\title{
Impact of Hyponatremia on Survival of Acute St- Elevation Myocardial Infarction Patients during 30 Days
}

\author{
Dr. Prashant Shringi ${ }^{1}$, Dr. S. R. Meena ${ }^{2}$
}

\begin{abstract}
Objective: Hyponatremia has been shown to be a predictor of cardiovascular mortality among patients with heart failure. Hyponatremia is intial insult for neurohormonal activation and left ventricular remodeling in acute myocardial infarction, both these factors are responsible with other factors for predicting short term survival in patient of acute myocardial infarctions. Hence we aimed to investigate the impact of hyponatremia in the setting of acute ST elevation MI and to determine its usefulness in predicting short term survival. Material and methods: 100 consecutive patients presenting with acute ST-elevation myocardial infarction admitted to M.B.S. HOSPITAL, G.M.C. KOTA, from aug 2013 to dec 2014 were studied. Qualifying patients underwent detailed history and clinical examination. Plasma sodium concentrations were obtained on admission and at 24, 48 and 72 hours thereafter. Hyponatremia was correlated with various parameters like age, male sex, diabetes, anterior infacrtion, killip class, mean ejection fracrtion. The primary end point was all cause mortality within 30 days following myocardial infarction. Results: In our study ,substantial proportion of patients who presented with acute ST elevation myocardial infarction were hyponatremic on admission or developed hyponatremia shortly after admission.Corelation of hyponatremia was found highly significant with male sex(pvalue=0.012),diabetes(p value=0.04),killip class( $p$ value=0.02),ejection fraction(p value=0.008),but no correlation was found with age,sex,smoking. We also found a significant linear relationship between severity of hyponatremia and mortality. Multivariate analysis was performed which identified hyponatremia on admission or early development of hyponatremia as a significant independent predictor of 30 day mortality. Conclusion: In our study we concluded that hyponatremia on admission or early development of hyponatremia in patients with acute ST elevation myocardial infarction is an independent predictor of 30-day mortality.
\end{abstract}

Keywords: Acute myocardial infarction, Hyponatremia, neurohrmonal activation, left ventricular remodeling , Mean EF

\section{Introduction}

Myocardial infarction is a well known clinical entity. It is one of the most fatal diseases which is world wide in distribution, affecting all races and nationalities. Myocardial infarction occurs due to imbalance between myocardial oxygen demand and coronary artery blood flow ${ }^{1}$.

An acute myocardial infarction causes a threat to circulatory homoeostasis, and the activation of various neuroendocrine systems is believed to be an attempt to readjust to both myocardial and systemic consequences of the destabilising event. Increased sympathetic nervous tone, enhanced activity of the circulating and local renin-angiotensin systems, and disturbed endocrine or paracrine function of the endothelium may all provoke vasoconstriction in the systemic and coronary vascular beds. Activation of the rennin angiotensin system also serves to induce salt and water retention and to expand circulating blood volume ${ }^{2,3}$.

Hyponatremia is a common electrolyte disorder amongst hospitalized patients ${ }^{4}$,especially in postoperative period ${ }^{5}$ and in patients with heart failure ${ }^{9}$ Hyponatremia has been shown to be a predictor of cardiovascular mortality among patients with heart failure ${ }^{67}$. In fact, the neurohormonal activation that accompanies acute myocardial infarction is similar to that which accompanies heart failure ${ }^{8}$.In myocardial infacrtion hyponatremia aggravated by concomitant activation of the rennin angiotensin system and increased catecholamine production sustained neurohormonal activation after myocardial infarction mainly occurs in patients with clinical heart failure and is related to the magnitude of myocardial damage, even in patients without heart failure. ${ }^{8}$
Hyponatremia is a simple marker of neurohormonal activation during the acute phase of myocardial infarction and predicts the short-term survival. ${ }^{10}$

\section{Materials and Methods}

100 consecutive patients presenting with acute ST-elevation Myocardial infarction admitted to M.B.S. hospital, G.M.C.. kota, were studied. The study was carried out on patients presenting with acute ST-elevation Myocardial infarction.Those patients who had myocardial infarction without ST elevation were excluded from study. This study was be done on sample of 100 patients.

Qualifying patients i. e.patients of acute Myocardial infarction who received thrombolytic therapy were undergo detailed history and clinical examination. Plasma sodium concentration were obtained on admission and at 24, 48and 72 hours. Plasma sodium concentration were obtained by using an ISE unit of EM-360 fully auto analyser. serum CPK MB level were be obtained. The primary end point was all cause mortality within 30 days following myocardial infarction.

Various routine investigations like lipid profile ,blood sugar s.urea ,s.creatinine etc. were done.

\section{Results}

In this study 100 patients of acute ST elevation myocardial infarction who had elevated serum cpkmb were studied .Out of 100 patients 80 were male and 20 were female. We divided patients of acute ST elevation $\mathrm{MI}$ in three subgroups. Group A,B,C.In group A,those patients who had normal sodium level, in group B those patients who 


\section{International Journal of Science and Research (IJSR) \\ ISSN (Online): 2319-7064}

Index Copernicus Value (2013): 6.14 | Impact Factor (2014): 5.611

developed hyponatremia on admission and in group $\mathrm{C}$ those who developed hyponatremia within $72 \mathrm{hrs}$ of admission. In our study we observed $17 \%$ patients of acute ST elevation MI developed hyponatremia on admission and $23 \%$ patients of acute ST elevation MI developed hyponatremia within 72 hrs of admission. While in sex wise distribution 15 males and 2 females developed hyponatremia on admission and within $72 \mathrm{hrs}$ of admission 17 males and 6 females developed hyponatremia.(Table no.1) In our study serum sodium level was statistically significant in determining mortality. In our study mean serum sodium level was $136.92 \pm 1.90$ in the survivors and $134.8 \pm 3.52$ in the non survivors.

In our study we observed that old age patients had more chances for developing of hyponatremia, In our study mean age is $51.8 \pm 12.15$ who had normal sodium level, mean age is $55.8 \pm 10.8$ who developed hyponatremia on admission and mean age is $53.71 \pm 9.54$ who developed hyponatremia within $72 \mathrm{hrs}$ of admission.

In our study, in patients of acute ST elevation MI serum sodium, level correlated with age ,male sex, diabetes, smoking hypertension, anterior infarction, killip class ,mean ejection fraction. Outcome of study was seen in the form of 30 days mortality in the patients who developed acute ST elevation myocardial infarction.

In our study patients who presented or developed hyponatremia on admission had diabetes(29\%), anterior infarction (16\%), higher Killip class(1.11\%) and lower ejection fraction $(41.1 \pm 10.03 \%)$.Corelation of hyponatremia was found highly significant with diabetes( $\mathrm{p}$ value $=0.0004$ ), anterior infarction $(\mathrm{p} \quad$ value $=0.003)$,killip $\operatorname{class}(\mathrm{p}$ value $=0.0008)$, mean ejection fraction $(\mathrm{p}$ value $<0.001)$ while it was not found significant with age, smoking and hypertension.(Table No.2)

We observed impact of hyponatremia in patient of acute ST elevation MI as 30 days survival. For this we divided paients in to two groups survinors and non survivorsand correlates various factors in survivors and nonsurvivors(Table No3)

In our study 10 deaths $(10 \%)$ occurred within 30 days of admission, 5\% (3/60) in patients without hyponatremia, $17.64 \%(3 / 17)$ in patients with hyponatremia on admission, $17.39 \%(4 / 23)$ in patients who developed hyponatremia within 72 hour of admission.

In multivariate logistic regression analysis hyponatremia remains independent predictor of mortality in patients of acute ST elevation myocardial infarction.

\section{Discussion}

In our study we found higher mortality in hyponatremic patients as well as significant linear relationship between severity of hyponatremia and mortality. We concluded that hyponatremia is a predictor for citically ill patients in acute myocardial infarction. Goldberg A et al in their study of 978 patients have concluded that early hyponatremia is a simple marker of neurohormonal activation during the acute phase of myocardial infarction and predicts the long-term development of heart failure and death. ${ }^{10}$

Sigurdsson A, Held P, Swedberg K in their study of 55 patients with acute myocardial infarction concluded that sustained neurohormonal activation after myocardial infarction mainly occurs in patients with clinical heart failure and is related to the magnitude of myocardial damage, even in patients without heart failure. ${ }^{8}$

Tang et al also documented in their study that hyponatremia was independentaly associated with in hospital death and heart failure ${ }^{11}$

In our study we also found that hyponatremia is also associated with old age, dibetes and higher killip class.

Chiara lazzeri et al conducted a study from 2004 to 2010 on 1231 patients in their study they have shown two important results 1 hyponatremia is common finding being associated mainly with older age, diabetes and advanced killip class 2 . Patients with hyponatremia had higher rates of in hospital and long term mortality. ${ }^{12}$

We also documented that hyponatremia is strongly associated with male sex (pvalue $=0.012)$, diabetes ( $p$ value $=0.0004)$, anterior infarction $(\mathrm{p} \quad$ value $=0.003)$, killip $\operatorname{class}(\mathrm{p}$ value $=0.0008)$ and low mean ejection fraction in a patient of acute ST elevation myocardial infarction. Gold berg et al In present study patients who presented or developed hyponatremia on admission had diabetes(29\%), anterior infarction (16\%), higher Killip class(1.11\%) and lower ejection fraction( $41.1 \pm 10.03 \%$ ). This is in accordance to the study conducted by Goldberg ${ }^{39}$ et al. In Goldberg et al study patients those were developed hyponatremia on admission also had diabetes (43\%), anterior infarction(49\%), higher killip class(1.6 \pm 1.0$)$, and lower $\operatorname{EF}(42 \pm 13 \%)$.

In our study 10 deaths (10\%) occurred within 30 days of admission, $5 \%(3 / 60)$ in patients without hyponatremia, $17.64 \%(3 / 17)$ in patients with hyponatremia on admission, $17.39 \%(4 / 23)$ in patients who developed hyponatremia within 72 hour of admission. Similar study done by Goldberg ${ }^{10}$ et al,in which a total of 105 deaths (10\%) occurred within 30 days of admission. 6.2\% (44/708) of patients without hyponatremia, $19.8 \%(26 / 131)$ of patients with hyponatremia on admission and $16.8 \%$ (35/208) of patients who developed fhyponatremia after admission.

\section{Conclusion}

Hyponatremia has been shown to be a predictor of cardiovascular mortality among patients with heart failure and acute anterior wall MI. In our study we studied the impact of hyponatremia in predicting the shorterm survival within 30 days, we found higher mortality in hyponatremic patients as well as significant linear relationship between severity of hyponatremia and mortality.we concluded that hyponatremia on admission or early development of hyponatremia in patients with acute ST elevation myocardial infarction is an independent predictor of 30-day mortality. Plasma sodium levels may serve as a simple marker to identify patients at risk. 


\section{International Journal of Science and Research (IJSR)}

ISSN (Online): 2319-7064

Index Copernicus Value (2013): 6.14 | Impact Factor (2014): 5.611

Table 1: Comparative study of group $\mathrm{ABC}$ with various variables

\begin{tabular}{|c|c|c|c|c|}
\hline \multirow{2}{*}{ Characteristics } & $\begin{array}{c}\text { Normal sodium level } \\
(\mathrm{n}=60) \mathrm{A}\end{array}$ & $\begin{array}{c}\text { Hyponatremia on Admission } \\
(\mathrm{n}=17) \mathrm{B}\end{array}$ & $\begin{array}{c}\text { Hyponatremia within } 72 \\
\text { hrs }(\mathrm{n}=23) \mathrm{C}\end{array}$ & $\mathrm{P}$ value \\
\cline { 2 - 5 } & \multicolumn{4}{|c|}{ Mean \pm SD, Number $(\%)$ or Median } \\
\hline Age (Yrs) & $51.8 \pm 12.15$ & $55.8 \pm 10.8$ & $53.71 \pm 9.54$ & 0.413 \\
\hline Male sex & $48(60 \%)$ & $16(20 \%)$ & $16(20 \%)$ & 0.16 \\
\hline Diabetes & $7(29 \%)$ & $9(37 \%)$ & $8(33 \%)$ & 0.0004 \\
\hline Smoking & $24(63 \%)$ & $7(18 \%)$ & $7(18 \%)$ & 0.695 \\
\hline Hypertension & $14(56 \%)$ & $2(8 \%)$ & $9(36 \%)$ & 0.1212 \\
\hline Anterior Infarction & $48(67 \%)$ & $12(16 \%)$ & $12(16 \%)$ & 0.0039 \\
\hline Killip Class & $1.01 \pm 0.12$ & $1.11 \pm 0.33$ & $1.08 \pm 0.28$ & 0.0008 \\
\hline Ejection Fraction (\%) & $52.95 \pm 9.01$ & $41.1 \pm 10.03$ & $48.9 \pm 10.67$ & $\mathrm{p}<0.001$ \\
\hline
\end{tabular}

Group A : patients with normal sodium levels

Group B : hyponatremia on admission

Group C: hyponatremia with in 72 hours

Table 3: Comparative study of group survivors and nonsurvivors for various variables

\begin{tabular}{|c|c|c|c|c|}
\hline & Surviors GroupA & Non Survivors Group B & T value & $P$ value \\
\hline $\mathrm{N}$ & 90 & 10 & & \\
\hline Age (Yrs) ( mean \pm SD) & $52.31 \pm 10.9$ & $57.8 \pm 14.5$ & 1.61 & 0.272 \\
\hline Sex (Male) & 75 & 5 & \multirow[t]{2}{*}{2.55} & \multirow[t]{2}{*}{0.012} \\
\hline Sex (Female) & 15 & 5 & & \\
\hline Hyponatremia (mean \pm SD) & $136.92 \pm 1.90$ & $134.7 \pm 3.52$ & 3.026 & 0.0032 \\
\hline Smoking & 35 & 4 & 0.07 & 0.945 \\
\hline Diabetes & 19 & 5 & 2.05 & 0.0429 \\
\hline Hypertension & 20 & 5 & 2 & 0.0484 \\
\hline Infarct site Anterior & 65 & 7 & \multirow[t]{2}{*}{0.137} & \multirow[t]{2}{*}{0.893} \\
\hline Inferior & 17 & 3 & & \\
\hline Killip Class I & 86 & 7 & \multirow[t]{2}{*}{2.7} & \multirow[t]{2}{*}{0.0234} \\
\hline Killip Class II & 4 & 3 & & \\
\hline $\mathrm{EF}(\%)($ mean \pm SD) & $49.74 \pm 10.71$ & $40.2 \pm 8.31$ & 2.7 & 0.008 \\
\hline
\end{tabular}

Table 2 Showing comparative study of Hyponatremia in various groups like Diabetes ,Mean EF(\%),Killip class, AWMI in

Three study groups(A,B,C)

\begin{tabular}{|l|l|l|l|l|}
\hline Groups & Diabetes & Mean EF(\%) & Killip class & AWMI \\
\hline Normalsodium level(A) & $29 \%$ & $52.95 \pm 9.01$ & 1.01 & $67 \%$ \\
\hline Hyponatremia on admission(B) & $37 \%$ & $41.1 \pm 10.03$ & 1.11 & $16 \%$ \\
\hline Hyponatremia within 72 hrs(C) & $33 \%$ & $48.9 \pm 10.67$ & 1.08 & $16 \%$ \\
\hline
\end{tabular}

\section{References}

[1] Antman EM, Braunwald E. ST segment elevation mycocardial Infarction In : Zipes, Libby, Bonow, Mann editors. Braunwalds Heart disease a text book of cardiovascular medicine. 9th edn. Philadelphia: Elsevier Saunders; 2012. p.1087-1176.

[2] Jonko Remes;British Heart J.[supplement]1994;72:6569.

[3] St. John Sutton, Norman Sharpe; Left ventricular Remodeling after Myocardial Infarction,AHA Journal Circulation. 200;101;2981-2988.

[4] Anderson RJ, Chung HM, Kluge R, Schrier RW. Hyponatremia: a prospective analysis of its epidemiology and the pathogenetic role of vasopressin. Ann Intern Med. 1985 Feb;102(2):164-8.

[5] Chung HM, Kluge R, Schrier RW Anderson RJ. Postoperative hyponatremia,A prospective study. Arch Intern Med. 1986;146:333-336.

[6] Lee WH, Packer M. Prognostic importance of serum sodium concentration nand its modification by converting-enzyme inhibition in patients with severe chronic Hyponatremia. Circulation. 1986;73:257-267.
[7] Saxon LA, Stevenson WG, Middlekauff HR, et al. Predicting death from progressive heart failure secondary to ischemic or idiopathic dilated cardiomyopathy. Am J Cardiol.1993;72:62-65.

[8] Sigurdsson A,Held P,Swedberg K.Short and long-term neurohormonal activation following acute myocardial infarction. Am Heart J.1993; 126:1068-1076.

[9] Biswas M, Davies JS. Hyponatremia in clinical practice. Post grad Med J2007; 83:373-378.

[10] Goldberg A, Hammerman H, Petcherski S. Zdorovyak A, Yalonetsky S.Kapeliovich M. Prognostic importance of hyponatremia in acute ST-elevation myocardial infarction. Am J Med. 2004; 117:242-248.

[11] Tang Q, Hua Q. Reationship between and in-hospital outcomes in Chinese patients with ST-elevation myocardial infarction.Intern Med 2011;50:969-974.

[12] Chiara lazzeri ;serfina valenite;marco chiostri; poala attana Claudiopicariello; gian franco gensini et al.usefulness of hyponatremia in the acute phase of stelevation myocardial infarction as a marker of severity AMJcardiol2012;110:1419-1424. 